\title{
Exploring Attributes of High-Value Primary Care
}

Melora Simon, $M P H^{1}$

Niteesh K. Choudhry, MD, $P b D^{2}$

Jim Frankfort, $M D^{3}$

David Margolius, $M D^{4}$

Julia Murpby, MSc ${ }^{1}$

Luis Paita, $\mathrm{PbD}^{3}$

Thomas Wang, $P b D^{1}$

Arnold Milstein, MD, MPH

${ }^{1}$ Clinical Excellence Research Center, Stanford University, Stanford, California

${ }^{2}$ Center for Healthcare Delivery Sciences, Brigham and Women's Hospital and Harvard Medical School, Boston, Massachusetts

${ }^{3}$ QuintilesIMS, Durham, North Carolina

${ }^{4}$ Case Western Reserve University, School of Medicine, Cleveland, Ohio
Conflicts of interest: autbors report none.

\section{CORRESPONDING AUTHOR}

Arnold Milstein, MD, MPH Clinical Excellence Research Center, Stanford University 75 Alta Road

Stanford, CA 94305

amilstein@stanford.edu

\begin{abstract}
PURPOSE Medicare's merit-based incentive payment system and narrowing of physician networks by health insurers will stoke clinicians' and policy makers' interest in care delivery attributes associated with value as defined by payers.
\end{abstract}

METHODS To help define these attributes, we analyzed 2009 to 2011 commercial health insurance claims data for more than 40 million preferred provider organization patients attributed to over 53,000 primary care practice sites. We identified sites ranking favorably on both quality and low total annual per capita health care spending ("high-value") and sites ranking near the median ("average-value"). Sites were selected for qualitative assessment from 64 highvalue sites and 102 average-value sites with more than 1 primary care physician who delivered adult primary care and provided services to enough enrollees to permit meaningful spending and quality ranking. Purposeful sampling ensured regional diversity. Physicians experienced in primary care assessment and blinded to site rankings visited 12 high-value sites and 4 average-value sites to identify tangible attributes of care delivery that could plausibly explain a high ranking on value.

RESULTS Thirteen attributes of care delivery distinguished sites in the highvalue cohort. Six attributes attained statistical significance: decision support for evidence-based medicine, risk-stratified care management, careful selection of specialists, coordination of care, standing orders and protocols, and balanced physician compensation.

CONCLUSIONS Awareness of care delivery attributes that distinguish their high-value peers may help physicians respond successfully to incentives from Medicare and private payers to lower annual health care spending and improve quality of care.

Ann Fam Med 2017;15:529-534. https://doi.org/10.1370/afm.2153.

\section{INTRODUCTION}

$\mathrm{T}$ o address criticisms that the US health system rewards volume of service rather than value, Medicare and some private payers are defining and rewarding high value health care. After a 4-year ramp-up period, Medicare's merit-based incentive payment system (MIPS) will adjust annual physician payment by as much as $9 \%$ in 2022, based primarily on measures of quality and efficient resource use. Physicians who join larger organizations participating in Medicare's advanced alternative payment models (APMs) will face parallel pressure from within these organizations to improve value of health care. Recent efforts, such as the patient-centered medical home recognition, designed to help physicians improve quality, have not reliably improved quality and lowered spending. ${ }^{1-3}$ This lack of improvement may be due to the absence of evidence on what physicians can do to attain both low per capita spending and favorable quality scores for nonMedicare as well as Medicare populations. Prior research on total per capita health care spending and quality has used Medicare data to compare regions and examined larger organizations such as hospitals and their affiliated physicians. ${ }^{4}$ We initiated an exploratory study to address these limitations for physicians facing intensifying pressure to improve value. 


\section{METHODS}

\section{Study Design}

Our hypothesis-generating mixed methods study of a small national sample of primary care practice sites sought to reveal attributes of primary care delivery associated with high value. ${ }^{5-8}$ The study was granted exempt status by the Stanford Institutional Review Board.

\section{Data Sources and Ranking of Primary Care Practices} To rank US primary care practice sites on average annual health care spending per patient, we used claims from 2009 through 2011 from the PharmetricsPlus data set that includes over 40 million US commercial health insurance plan enrollees. ${ }^{9-11}$ The OneKey data set from IMS Quintiles ${ }^{12}$ was used to group self-identified primary care physicians who practiced at the same office site.

We attributed patients to the physician practice with the most claims in a calendar year. We excluded practices with fewer than 30 attributed patients. We excluded practices with 1 practitioner, concerned that a site visit would be too disruptive. Since the absence of a national all-payer claims database requires analysis of small patient sample sizes per site, ${ }_{1}^{13}$ we used an independent scientific panel to make analytic decisions as detailed in the Supplemental Appendix, available at http://www.annfammed.org/content/15/6/529/suppl/

DC1/. The panel was composed of individuals who had published assessments in journals with high impact factors of the validity of measures of physician resource use and/or quality of care or had applied such measures in high-impact journals.

For each practice site, we calculated an observedto-expected measure of total risk-adjusted spending per patient-year for attributed patients. We also calculated spending by service category. Details of our approach are provided in the Supplemental Appendix (available at http://www.annfammed.org/content/15/6/529/ suppl/DC1/). To rank practices on quality, we created a composite score based on up to 41 measures calculable with claims data and endorsed by national quality organizations or used by the Centers for Medicare and Medicaid Services (CMS). These measures and the details of the composite formation are listed in the Supplemental Appendix. We assigned a practice to the high-value group if it ranked in the top quintile on both scores, and the average-value group if the practice ranked between the 50th percentile and $60^{\text {th }}$ percentile on both scores.

\section{Site Selection and Visits}

We visited high- and average-value sites between May 2013 and June 2014. In order to improve the likelihood of uncovering care attributes that are widely replicable, highly atypical practice sites operated by large multi-state health care organizations primarily subject to population-based payment such as the Veterans Health Administration and Kaiser Permanente were excluded, as were practice sites that did not self-identify as providing adult primary care. We performed purposeful sampling ${ }^{14}$ to produce a list of 17 high-value practices and 6 average-value practices. Purposeful sampling allowed inclusion of practices in all 4 census US regions, as well as regions with high and low penetration of managed care, and high and low prices for labor and nonlabor inputs as published by CMS. We telephoned sites from our list of selected sites and moved down the list when a site declined to be visited or did not respond to 3 calls. Twenty-nine percent of high-value practices and 33\% of averagevalue practices declined to participate or did not respond.

We visited 12 high-value sites, stopping when we reached thematic saturation. ${ }^{5,15}$ Our available funding allowed us to visit 4 sites in the average-value group.

Each 8 -hour visit was conducted by a primary care physician with experience in practice assessment and a nonphysician qualitative researcher (J.M.). Physicians were blinded as to whether each practice was in the high- or average-value group. A structured pre-visit call with each practice's designated physician representative elicited background information. Visiting teams used a semistructured interview guide using questions suggested by an advisory panel of primary care improvement experts and qualitative researchers familiar with prior research on primary care performance to interview physicians, practice managers, nurses, medical assistants, and receptionists. The interviews also included open-ended questions aimed at identifying attributes that interviewees felt might account for their practice site ranking favorably. The team gathered physician compensation information to compare with Medical Group Management Association (MGMA) norms. ${ }^{16}$ Immediately following the visit, 1 research team member (M.S.) debriefed the site visit team using a recorded structured telephone interview. The nonphysician took detailed field notes and the physician team member wrote a report listing attributes that could plausibly explain high value.

\section{Analysis}

Two authors (J.M., M.S.) and a research assistant grouped frequently observed practice attributes into conceptually distinct categories using content analysis and developed a scoring grid to assess the presence and degree of each attribute. If information pertaining to an attribute was not available in the written report, field notes, or debrief notes, we contacted the site's 


\section{Table 1. Characteristics of Visited Practice Sites Other Than Care Delivery Attributes}

\begin{tabular}{|c|c|c|}
\hline & $\begin{array}{c}\text { High-Value } \\
\text { Cohort } \\
(n=12)\end{array}$ & $\begin{array}{c}\text { Average-Value } \\
\text { Cohort } \\
(n=4)\end{array}$ \\
\hline No. (\%) Independently owned & $4(33)$ & $1(25)$ \\
\hline No. (\%) Multi-specialty group practices & $6(50)$ & $1(25)$ \\
\hline No. of physicians per practice, mean (SD) & $7(5)$ & $17(27)$ \\
\hline $\begin{array}{l}\text { No. of primary care physicians with } \\
\text { attributed patients, mean (SD) }\end{array}$ & $5(6)$ & $7(8)$ \\
\hline $\begin{array}{l}\text { No. of attributed patients per primary } \\
\text { care physician, mean (SD) }\end{array}$ & $46(405)$ & $599(507)$ \\
\hline Case mix index, mean (SD) & $1.3(0.5)$ & $1.1(0.2)$ \\
\hline $\begin{array}{l}\text { Allowed cost clinical risk group-adjusted } \\
\text { O/E spending ratio, mean (SD) }\end{array}$ & $0.66(0.11)$ & $0.94(0.01)$ \\
\hline $\begin{array}{l}\text { Mean number of quality measures } \\
\text { applicable to each practice }\end{array}$ & $24(6)$ & $33(10)$ \\
\hline $\begin{array}{l}\text { Weighted quality composite index } \\
\text { O/E ratio, mean (SD) }\end{array}$ & $1.14(0.04)$ & $0.99(0.00)$ \\
\hline \multicolumn{3}{|l|}{ No. (\%) by census region } \\
\hline Midwest & $2(17)$ & $1(25)$ \\
\hline Northeast & $3(25)$ & $1(25)$ \\
\hline South & $3(25)$ & $1(25)$ \\
\hline West & $4(33)$ & $1(25)$ \\
\hline
\end{tabular}

primary care. Two additional high-value practices were excluded because they were Veteran Affairs sites.

Characteristics other than attributes of care delivery of the 12 high-value and 4 average-value practices that were visited are displayed in Table 1. The high-value cohort compared with the average-value cohort had fewer total physicians ( 7.5 vs $17.0)$ and primary care physicians (5.3 vs 6.8). The practices in both cohorts were evenly distributed through 4 census regions by design. A similar distribution of practices from each cohort both received substantial value-based payment from payers and paid their physicians above the MGMA average for their specialty.

\section{Components of Lower Spending}

The largest differences in spending between high-value and average-value cohorts (Table 2) occur in inpatient surgical services, outpatient hospital visits and ambulatory surgical services, and outpatient prescription medications, including

representative and used open-ended questions to score its presence. For example, we asked: "How do you manage patients' health care needs outside of clinic hours?" Responses were scored on a 5-point scalewith 5 representing the fullest implementation of an attribute and 1 representing its absence-or simply as "present" or "absent" for dichotomous attributes. The scoring approach is further described in the Supplemental Appendix.

We identified the associations between the presence of each attribute and each practice sites' value cohort by using a 2-tailed comparison with a significance threshold of $P<.05$. Ordinal variables were compared using a Mann-Whitney test. Dichotomous variables were compared using a Fisher's Exact test. Statistical analysis was conducted using Stata version 14.1 (StataCorp LP).

\section{RESULTS}

\section{Practice Selection and Characteristics}

Patients were attributed to 53,773 practices. After we excluded practices with a single practitioner, 6,546 remained of the 9,910 practices meeting minimum patient sample size requirements for ranking. Of these, 64 ranked in the top quintile for both spending and quality and 102 ranked in the decile above the mean. Nine high-value and 13 average-value practices were excluded because they did not primarily deliver adult infusions and other specialty pharmaceuticals not dispensed from retail pharmacies. Spending in other service categories was similar between the 2 cohorts. Per capita spending differences were attributable to differences in the frequency of service utilization. The contribution of differences in average unit prices payable per service was not significant.

Table 2. Per-Patient Per-Month Spending Details by Practice Cohort

\begin{tabular}{lcc}
\hline $\begin{array}{l}\text { PPPM Spending, } \\
\text { Mean (SD) \$ }\end{array}$ & $\begin{array}{c}\text { High-Value } \\
\text { Cohort }\end{array}$ & $\begin{array}{c}\text { Average- } \\
\text { Value Cohort }\end{array}$ \\
\hline Total inpatient & $42(27)$ & $63(19)$ \\
Inpatient maternity & $3(5)$ & $1(3)$ \\
Inpatient medical & $21(15)$ & $16(14)$ \\
Inpatient surgical & $19(18)$ & $46(6)$ \\
Emergency department & $20(13)$ & $21(3)$ \\
Outpatient hospital/ambulatory & $48(16)$ & $73(39)$ \\
$\quad$ surgery center & $41(8)$ & $39(9)$ \\
Office & $44(13)$ & $49(13)$ \\
Diagnostics & $20(6)$ & $25(5)$ \\
Laboratory & $24(9)$ & $24(10)$ \\
Imaging & $78(20)$ & $111(7)$ \\
Prescription medications ${ }^{a}$ & & $35(18)$ \\
& $20(9)$ & \\
Other & & \\
\hline PpPM = per-patient-per-month. & & \\
a Prescription medications includes both prescription claims and office/ & \\
outpatient-administered medications/injections/infusions. & \\
\hline
\end{tabular}




\section{Attributes More Frequently Found in the High-Value Cohort}

We found 13 attributes associated with the high-value cohort (Table 3).

\section{Distinguishing Attributes that Reached Statistical Significance}

Despite the small sample of visited sites, 6 of the 13 attributes reached our predetermined cut point of statistical significance $(P<.05)$ : decision support for evidence-based medicine, risk-stratified care management, careful selection of specialists, coordination of care, standing orders and protocols, and balanced compensation. Scores are displayed in Tables 4 and 5.

\section{DISCUSSION}

The 6 attributes that statistically distinguished highvalue primary care practice sites cohere around 3 themes. Risk-stratified care management, careful selec- tion of specialists, and coordination of care reflect physician recognition of the need for "care traffic control" to help patients with complex conditions or treatment plans navigate the hazardous streets of a fragmented US health care system. The multi-decade failure of payer efforts to serve effectively in this role in isolation from primary care sites via telephonically mediated nurse case managers suggests that primary care represents an advantaged platform for care coordination. Physician success in adopting these 3 attributes will require much more easily accessible information on all care being received by patients as well as greater transparency on how other physicians perform relative to peers. Public and private efforts to address both needs remains slow but steady as illustrated by federal encouragement of inter-physician exchange of data from electronic health records and liberalization of Medicare's rules for Qualified Entities providing physician performance comparisons.

Two distinguishing attributes, decision support

Table 3. Attributes More Frequently in High-Value Practices Relative to Average-Value Practices ${ }^{a}$

\begin{tabular}{|c|c|}
\hline Attribute & Description \\
\hline Expanded access & $\begin{array}{l}\text { Practices offer same-day appointments and accommodate walk-ins, extend evening and weekend hours, and } \\
\text { often take their own after-hours calls with access to their patients' electronic medical records. }\end{array}$ \\
\hline $\begin{array}{l}\text { Decision support for evi- } \\
\text { dence-based medicine }\end{array}$ & $\begin{array}{l}\text { The care team ensures that patients receive all evidence-based care and treatment, often by making guideline- } \\
\text { based reminders available to clinicians in the electronic medical record. Some practice office managers regularly } \\
\text { run reports to identify care gaps to alert the care team to take action-such as a list of patients overdue for } \\
\text { colorectal cancer screening. Physicians consciously avoid ordering tests that would not change management. }\end{array}$ \\
\hline $\begin{array}{l}\text { Risk-stratified care } \\
\text { management }{ }^{a}\end{array}$ & $\begin{array}{l}\text { Each patient receives support that is matched to his or her unique needs. High-risk patients are monitored and } \\
\text { advised by a care manager, scheduled for longer office visits, receive frequent phone checks by office staff, or } \\
\text { in some cases, clinician home visits. }\end{array}$ \\
\hline $\begin{array}{l}\text { Shared decision-making and } \\
\text { advanced care planning }\end{array}$ & $\begin{array}{l}\text { When diagnostic and treatment options substantially differ in their consequences and cost such as care near the } \\
\text { end of life, clinicians walk patients through likely scenarios and tradeoffs. }\end{array}$ \\
\hline Complaints are gold & $\begin{array}{l}\text { Complaints from patients are perceived to be as valuable as compliments, if not more so. Practices take every } \\
\text { opportunity to encourage patient feedback. }\end{array}$ \\
\hline Comprehensive primary care & $\begin{array}{l}\text { Clinicians practice within the full scope of their expertise, including services that primary care clinicians often } \\
\text { refer out, such as skin biopsies, suturing, insulin initiation and stabilization, joint injections, and IUD place- } \\
\text { ment. In some cases, such as treadmill testing, practices arrange training and supervision by specialists. }\end{array}$ \\
\hline $\begin{array}{l}\text { Careful selection of } \\
\text { specialists }^{a}\end{array}$ & $\begin{array}{l}\text { When services outside the scope of the primary care practice are necessary, primary care clinicians rely on a } \\
\text { carefully selected list of specialists with whom they trust to follow evidence-based guidelines and remain in } \\
\text { close contact as treatment plans develop. }\end{array}$ \\
\hline 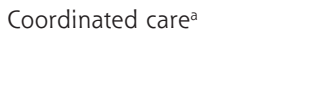 & $\begin{array}{l}\text { Care teams monitor patients outside of primary care visits. They ensure patients complete referrals to specialists } \\
\text { and schedule timely follow-up after unexpected hospitalizations. In some cases, they track medication adher- } \\
\text { ence by communicating with pharmacies or counting refills. }\end{array}$ \\
\hline Upshifted staff roles & $\begin{array}{l}\text { Physicians are supported by a team of medical assistants, front desk staff, and in some cases, nurses and } \\
\text { advanced practice clinicians who practice near the full potential of their education, skills, and licensure. As a } \\
\text { result, physicians devote more time to the most complex patients. }\end{array}$ \\
\hline $\begin{array}{l}\text { Standing orders and } \\
\text { protocols }\end{array}$ & $\begin{array}{l}\text { Practices develop standing orders and protocols for uncomplicated acute illnesses and chronic disease manage- } \\
\text { ment. Nonclinician team members use these standardized workflows to care for patients without requiring } \\
\text { direct clinician intervention. }\end{array}$ \\
\hline Shared work spaces & $\begin{array}{l}\text { Care teams including clinicians and nonclinicians work together in a common work area, enabling face-to-face } \\
\text { communication that facilitates problem-solving in real-time. }\end{array}$ \\
\hline Balanced compensation ${ }^{a}$ & $\begin{array}{l}\text { Physician salary is linked to value instead of only volume. Compensation reflects performance on at least one of } \\
\text { the following components: (1) quality of care, (2) patient experience, (3) resource utilization, and (4) contribu- } \\
\text { tion to practice-wide improvement activities. }\end{array}$ \\
\hline $\begin{array}{l}\text { Low overhead space and } \\
\text { equipment }\end{array}$ & $\begin{array}{l}\text { Practices rent modest offices and typically invest in laboratory, imaging, and other equipment only if it allows } \\
\text { clinicians to provide care more efficiently than referring to outside services. Some practices partner with other } \\
\text { practices to jointly operate imaging equipment at a lower cost per study. }\end{array}$ \\
\hline
\end{tabular}


Table 4. Attribute Score Comparison-Ordinally Scored Attributes ${ }^{a}$

\begin{tabular}{|c|c|c|c|}
\hline Attribute & $\begin{array}{c}\text { High-Value } \\
\text { Cohort Median } \\
\text { (IQR) }\end{array}$ & $\begin{array}{c}\text { Average-Value } \\
\text { Cohort Median } \\
\text { (IQR) }\end{array}$ & $\begin{array}{c}\text { P } \\
\text { (Mann- } \\
\text { Whitney) }\end{array}$ \\
\hline Expanded access & $4(1)$ & $3(0.75)$ & .065 \\
\hline $\begin{array}{l}\text { Decision support for evidence- } \\
\text { based medicine }\end{array}$ & $4(2)$ & $3(0.5)$ & .020 \\
\hline Risk-stratified care management & $4(1.125)$ & $2(0.25)$ & .012 \\
\hline $\begin{array}{l}\text { Shared decision making and } \\
\text { advanced care planning }\end{array}$ & $4(0.25)$ & $3(0.5)$ & .056 \\
\hline Complaints are gold & $3.5(3)$ & $2.5(1)$ & .709 \\
\hline Comprehensive care & $4(0.25)$ & $3.5(1.5)$ & .590 \\
\hline Careful selection of specialists & $4(1.25)$ & $3(0.25)$ & .013 \\
\hline Coordinated care & $4(2)$ & $2(0.25)$ & .006 \\
\hline Upshifted staff roles & $5(1)$ & $2.5(1.5)$ & .058 \\
\hline Standing orders and protocols & $3.5(1)$ & $1.5(1.25)$ & .020 \\
\hline
\end{tabular}

High-value practices had fewer attributed patients than the averagevalue practices. We do not know if this reflects smaller panel sizes or fewer patients represented in the private health insurance database available for this study. High-value practices also qualified for assessment on fewer quality measures. This difference may reflect a different mix of patients treated by the high-value cohort relative to peers. Though we sampled locations with high and low managed-care penetration and input costs, we were unable to sample on other characteristics, such as practice size, that may also affect rankings on value.

Though our on-site assessments revealed attributes applied to all patients regardless of payer type, our findings may have differed if we had been able to rank with an all-payer database. When, and if, a national all-payer claims database linked to clinical data becomes available to US researchers, its greater patient diversity and sample size per physician will warrant greater confidence. We are a nation that seeks to lower the cost of good care,

for evidence-based medicine and standing orders and protocols, represent tools to ease cognitive burden for physicians and their staff. They can help tame the overwhelming flow of outcome studies and clinical guidelines, the widening array of disease subtypes likely to grow quickly with planned national investments in precision medicine, and the complexity of treatment plans for aging populations. The 6th attribute-balanced compensation—signals the usefulness of echoing within a practice external efforts to reward value rather than volume.

Differences in annual spending between the 2 cohorts were mostly explained by differences in spending for inpatient surgical services, outpatient hospital visits and ambulatory surgical centers, and outpatient prescription medications. Our finding differs from prior studies based on Medicare beneficiaries that find greater variation in population-wide spending for medical inpatient and home health services..$^{17}$ The difference may reflect greater illness burden of Medicare patients compared with younger, privately insured adults.

Given the relatively small number of study sites examined in this exploratory, hypothesis-generating study and non-random selection of sites for on-site visits, our findings should be regarded with caution. but lacks databases required to readily identify clinical teams that attain high quality with less spending.

A more costly, larger follow-up study using allpayer data and experiments to transfer these attributes to less-favorably ranking clinicians is warranted. Meanwhile, physicians seeking to respond to payer incentives to improve value now may benefit from considering "care traffic control" and other attributes of their primary care peers whom we found to rank favorably on performance measures typically used by payers. While large health systems draw attention for leading national efforts to improve the value of care, mary care practice sites can also achieve high value. The $34 \%$ lower spending (Table 1) attained by the high-value cohort suggests that investments in primary care refinement are a uniquely promising step on our national quest for more with less.

To read or post commentaries in response to this article, see it

Key words: primary health care; patient care team; health care costs; patient-centered care; guideline adherence; chronic disease; referral and consultation; decision making; specialization; standing orders

Submitted March 5, 2017; submitted, revised, July 21, 2017; accepted August 22, 2017. our study suggests that small community-based prionline at http://www.AnnFamMed.org/content/15/6/529. 
Funding support: This study and manuscript were made possible by a grant from the Peterson Center on Healthcare. The statements made and views expressed are solely the responsibility of the authors. The funding source played no role in design and conduct of the study, collection, management, analysis, and interpretation of the data, preparation, review, or approval of the manuscript and decision to submit the manuscript for publication.

Previous presentation: Before the completion of the analysis portrayed in this manuscript, an early, high-level summary of findings was presented at an event hosted by the Peterson Center on Healthcare in Washington, DC in December 2014. The content presented, which was equivalent to abstract-level findings, can be found on their website at http://petersonhealthcare.org/ identification-uncovering-americas-most-valuable-care.

Author Contributions: Conception and research design: A.M., M.S., T.W.; Acquisition of data: J.F., J.M., L.P., M.S., T.W.; Analysis and interpretation of data: A.M., J.F., L.P, T.W., J.M, M.S., N.K.C, D.M.; Drafting of the manuscript: D.M., M.S., T.W., A.M.; Critical revision of the manuscript for important intellectual content: - all authors; Final approval of the manuscript: - all authors; Obtaining of funding: A.M., M.S.; Administrative, technical, or material support: T.W., J.M., M.S.

Acknowledgments: The authors gratefully acknowledge the contributions of measurement methodology panelists John L. Adams, PhD, MS, Kaiser Permanente; Ashish K. Jha, MD, MPH, Harvard University; Mark Rattray, MD, CareVariance; Patrick Romano, MD, MPH, FACP, FAAP, University of California at Davis; and J. William Thomas, PhD, MBA, University of Michigan, as well as Scott Robertson, M. Econ, RN for statistical analysis. In addition, we thank current and former members of our research staff and the clinicians who led our site visits. These contributors were provided with financial support for the time they devoted to this project.

Supplemental Materials: Available at http://www.AnnFamMed. org/content/15/6/529/suppl/DC1/.

\section{References}

1. Friedberg MW, Schneider EC, Rosenthal MB, Volpp KG, Werner RM. Association between participation in a multipayer medical home intervention and changes in quality, utilization, and costs of care. JAMA. 2014;311(8):815-825.

2. Berwick DM, Nolan TW, Whittington J. The triple aim: care, health, and cost. Health Aff (Millwood). 2008;27(3):759-769.

3. Rosenthal MB, Friedberg MW, Singer SJ, Eastman D, Li Z, Schneider EC. Effect of a multipayer patient-centered medical home on health care utilization and quality: the Rhode Island chronic care sustainability initiative pilot program. JAMA Intern Med. 2013;173(20): 1907-1913.
4. Fisher ES, Bynum JP, Skinner JS. Slowing the growth of health care costs-lessons from regional variation. N Engl J Med. 2009;360(9): 849-852.

5. Marsh DR, Schroeder DG, Dearden KA, Sternin J, Sternin M. The power of positive deviance. BMJ. 2004;329(7475):1177-1179.

6. Bradley EH, Curry LA, Ramanadhan S, Rowe L, Nembhard IM, Krumholz HM. Research in action: using positive deviance to improve quality of health care. Implement Sci. 2009;4:25.

7. Sinsky CA, Willard-Grace R, Schutzbank AM, Sinsky TA, Margolius $D$, Bodenheimer $T$. In search of joy in practice: a report of 23 high-functioning primary care practices. Ann Fam Med. 2013;11(3):272-278.

8. Milstein A, Gilbertson E. American medical home runs. Health Aff (Millwood). 2009;28(5):1317-1326.

9. Divino V, Karve S, Gaughan A, DeKoven M, Gao G, Lanasa M. Healthcare utilization and costs among patients with hairy cell leukemia: analysis of a large US administrative claims database. Blood. 2015;126(23):4520.

10. McQueen R, Livingstone T, Vollmer T, Corboy J, Nair K, Campbell J. Decreased relapse activity for those who switch to Natalizumab from alternative disease modifying therapies: an observational study. Neurology. 2015;84(14):(suppl P3.272).

11. Edwards N, Phillips A, Locklear J. Age-, sex-, and geographic region-specific comorbidity in patients with multiple sclerosis. Paper presented at: American Academy of Neurology's 68th Annual Meeting; April 17, 2016; Vancouver, BC, Canada.

12. McClellan SR, Casalino LP, Shortell SM, Rittenhouse DR. When does adoption of health information technology by physician practices lead to use by physicians within the practice? J Am Med Inform Assoc. 2013;20(e1):e26-e32.

13. Adams JL, Mehrotra A, Thomas JW, McGlynn EA. Physician cost profiling-reliability and risk of misclassification. $N$ Engl J Med. 2010;362(11):1014-1021.

14. Palinkas LA, Horwitz SM, Green CA, Wisdom JP, Duan N, Hoagwood K. Purposeful sampling for qualitative data collection and analysis in mixed method implementation research. Adm Policy Ment Health. 2015;42(5):533-544.

15. Given L. Data saturation. In: Given LM, ed. The SAGE Encyclopedia of Qualitative Research Methods. Thousand Oaks, CA: SAGE Publications Ltd; 2008.

16. Medical Group Management Association. MGMA DataDive Provider Compensation 2013. Englewood, CO: Medical Group Management Association; 2013.

17. Gnadinger T. Health policy brief: geographic variation in Medicare spending. Health Affairs Blog. http://www.healthaffairs.org/ healthpolicybriefs/brief.php?brief_id=109. Published Mar 6, 2014. 